\title{
Research Paper: The Association Between Early Maladaptive Schemas and Defense Styles With Hoarding Behaviour Among University Students
}

\author{
Rahim Yousefi $^{1}$ (D), Seyed Ghasem Seyed Hashemi ${ }^{1^{*}}$ (D), Leila Sohrabi ${ }^{1}$, Maryam Hossein Abadi²
}

1. Department of Psychology, Faculty of Psychology and Education, Azarbaijan Shahid Madani University, Tabriz, Iran.

2. Department of Psychology, Faculty of Psychology and Educational Sciences, Marvdasht Branch, Islamic Azad University, Marvdasht, Iran.

\begin{tabular}{|l|l|l}
\hline $\begin{array}{l}\text { Use vour device to san } \\
\text { and read the article online }\end{array}$ & $\begin{array}{l}\text { Chtation: Yousefi, R., Seyed Hashemi, S. Gh., Sohrabi, L., \& Hossein Abadi, M. (2018). The Association Between Early } \\
\text { Maladaptive Schemas and Defense Styles With Hoarding Behaviour Among University Students. Journal of Practice in Clinical } \\
\text { Psychology, 6(4), 223-230. http://dx.doi.org/10.32598/jpcp.6.4.223 }\end{array}$ \\
dol: $:$ http://dx.doi.org/10.32598/jpcp.6.4.223
\end{tabular}

\section{(i) (3)}

Funding: See Page 229

Article info:

Received: 29 Apr 2018

Accepted: $25 \mathrm{Jul} 2018$

Available Online: 01 Oct 2018

Keywords:

Hoarding disorder, Defence style, Early maladaptive schema, Students

\section{ABSTRACT}

Objective: Individuals suffering from hoarding disorder tend to collect objects, belongings, and riches excessively. They are not able to or do not want to throw away the throng of worthless and useless items they have aggregated. Some psychological factors, especially maladaptive schemas and immature defense mechanisms can play a crucial role in the development and maintenance of hoarding disorder. In this regard, the present study investigates the predictive role and relationship of early maladaptive schemas and defense styles in hoarding behaviours in students.

Methods: The present study was a population-based cross-sectional study carried out on 300 students (149 females and 151 males) of the Payame Noor University of Khoy City, Iran in the academic year 2016-2017. All participants completed the Young Schema Questionnaire-Short Form, the Defense Style Questionnaire, and the Saving Inventory-Revised. The obtained data were analyzed by descriptive statistics, the Pearson correlation coefficient, and multiple linear regression.

Results: The results showed a significant correlation between early maladaptive schemas and defense styles with hoarding disorder. Also, all three defense styles (mature, neurotic, and immature) $\left(\mathrm{R}^{2}=12 \%\right)$, and the domains of Impaired autonomy/performance and impaired limits $\left(\mathrm{R}^{2}=17 \%\right)$ could predict the hoarding disorder in students.

Conclusion: Considering the study result, it can be useful to set up cognitive behavioural and dynamic treatment interventions aiming at early maladaptive schemas and defense mechanisms in individuals suffering from hoarding disorder.

\section{* Corresponding Author:}

Seyed Ghasem Seyed Hashemi, MSc.

Address: Department of Psychology, Faculty of Psychology and Education, Azarbaijan Shahid Madani University, Tabriz, Iran.

Tel: +98 (41) 34327526

E-mail:seyedhashemi@azaruniv.ac.ir 


\section{Highlights}

- Neurotic and immature defense styles associate with hoarding behavior.

- Early maladaptive schemas associate with hoarding behavior.

- All of three defense styles and the domains of impaired autonomy/performance and impaired limits could predict the hoarding disorder in students.

\section{Plain Language Summary}

The role of Early Maladaptive Schemas (EMS) and defense mechanisms in Obsessive Compulsive Disorders (OCD) are obvious. Moreover, hoarding behavior, because of its symptoms, was regarded as a subcategory of OCD. The present study aimed to predict hoarding behavior in students based on the EMS and defense mechanisms. The results indicate that hoarding behavior and its components have a positive and significant relationship with neurotic and immature defense styles, but no significant relationship was found between hoarding behavior and mature defense styles, that all defense styles were able to predict this disorder. In addition, this research reveals that hoarding behavior and its components have a positive and significant relationship with EMS domains, and are able to predict hoarding behavior among the domains of EMS impaired autonomy/performance and impaired limits. Considering the study result, it can be useful to set up cognitive behavioral and dynamic treatment interventions aiming at early maladaptive schemas and defense mechanisms in individual's suffering from hoarding disorder.

\section{Introduction}

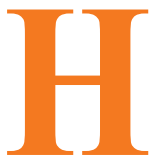

oarding Disorder (HD) is an extreme psychiatric condition leading to excessive aggregation of items which usually remained unused and accumulated. They create mess in the living place and significant trouble for the patient and others

(Frost, Steketee, \& Tolin, 2011). Studies have estimated the point prevalence of clinically significant hoarding behaviour in general population between $2 \%$ and $6 \%$ (American Psychiatric Association, 2013; Canale \& Klontz, 2013). This disorder is introduced as a type of obsessive-compulsive spectrum, which is classified separately as a disorder in this spectrum in the Diagnostic and Statistical Manual of Mental Disorders, $5^{\text {th }}$ Edition (DSM-5) (American Psychiatric Association, 2013).

Hoarding ranges from mild to severe and even reach a life-threatening stage (Frost, Steketee, \& Williams, 2000). Some factors contribute in the emergence and explanation of hoarding such as: 1 . Beliefs and concepts which reinforce the acquisition and maintenance of this condition; 2. Core beliefs regarding identity, competence, and interests. 3. Genetic predisposition; 4. Troubles with data processing, including decrease in focused attention, decision-making, and organising; 5 . High emotional attachment to the rich; 6. Deficiencies in cognitive processes; 7 . Maladaptive behaviors and be- liefs; and 8. Specific abnormalities in particular regions of brain, corresponding to executive function, impulse control, and reward processing (Kennedy \& O'Neill, 2012; Tolin, 2011).

Researchers have paid attention to the determining role of cognitive patterns and processes in hoarding behaviour and Obsessive-Compulsive Disorder (OCD). For instance, Frost and Hartel (1996) proposed a cognitive behavioural model for the explanation of hoarding behaviour for the first time, which considered the interaction of data processing deficiencies, defective beliefs about the essence of belongings, and the patterns of emotional avoidance. Also, Atalay, Atalay, Karahan and Caliskan (2008) reported that patients suffering from OCD had more active early maladaptive schemas compared to the general population. The concept of schema was first proposed by Beck (1967) and has received extensive empirical attention in the past few years.

Early Maladaptive Schemas (EMS) are defined as "self-defeating emotional and cognitive patterns that begin early in our development and repeat throughout life" (Young, Klosko, \& Weishaar, 2003). As elaborated by Young et al. (2003), each EMS has a potential which is the basis for development and maintenance of a range of Axis I and Axis II mental disorders (Taylor, Bee, \& Haddock, 2017). It is also recognised as an influential factor in obsessive-compulsive disorders (Atalay et al., 2008; 
Kim, Lee, \& Lee, 2014). Also, researchers and therapists have considered defense mechanisms and EMS, in the explanation of mental disorders (Walburg \& Chiaramello, 2015). Defense mechanisms have a particular significance in conceptualising and treating mental disorders from a psychodynamic perspective, and have benefited from special clinical and scholarly attention (Cramer, 2000).

People use certain defense mechanisms in confrontation with the internal and external stressful sources (Cramer, 2000). Defense mechanisms are divided into 3 groups of mature, neurotic, and immature, based on the level of their maturity (Bond, Gardner, Christian, \& Sigal, 1983). Defense mechanisms are patterned sensations, thoughts, and behaviours that are, to some extent, unintentional and arouse in response to danger conception (Vaillant, 1992).

Albucher, Abelson, and Nesse (1998) claimed that patients suffering from OCD, showed a significant change in their defense mechanisms after a 7-week behavioural therapy, which indicates the role of defense mechanisms in such disorders. Other studies reported similar results, e.g. Johansen, Krebs, Svartberg, Stiles and Holen (2011) reported that short-term psychodynamic and cognitive treatments on individuals with Cluster C personality disorders (obsessive-compulsive personality disorder, avoidant personality disorder, and dependent personality disorder) were accompanied by more changes in defense mechanisms and adaptation. Shabanpour, Zahiroddin, Janbozorgi and Ghaeli (2012) examined the defense mechanisms in individuals suffering from OCD and panic attack, in comparison to normal people. It was revealed that the clinical groups had higher immature styles compared to the normal group. In the etiology and description of HD, it is noted that "without any further specifications the term hoarding is of limited heuristic value" (Mataix Cols et al., 2010; Pertusa \& Fonseca, 2014; Maier, 2004).

Hoarding as a symptom can include a wide range of behaviours which are common among a variety of psychological disorders (Pertusa \& Fonseca, 2014). This disorder is commonly linked to OCD (25\% to $30 \%$ comorbidity). On the other hand, depression disorder is more prevalent in these individuals, and it also has many comorbidities, such as anxiety disorders, impulse control disorder, ADHD, and personality disorders (Wheaton \& Van Meter, 2014). As a problem for public health (Frost et al., 2000), hoarding behaviour calls for more investigation and research, to identify its risk factors and catch better insight for the prevention and treatment of this disorder. The role of EMS and defense mechanisms in obsessive-compulsive disorders are obvious. Moreover, hoarding behaviour was regarded as a subcategory of OCD due to its symptoms, thus, the present study aimed to predict hoarding behaviour in students based on the EMS and defense mechanisms.

\section{Methods}

This was a cross-sectional study and statistical population included all students aged 19-31 years (Mean $\pm \mathrm{SD}=24.03 \pm 3.05$ years) studying at Payame Noor University of Khoy City $(\mathrm{N}=1392)$, West Azerbaijan Province, Iran during the academic year 2016-2017. Sample size was 340 students, calculated according to Krejcie and Morgan (1970). Samples were selected using a two-stage cluster sampling design.

We selected participants from three faculties of Literature and Humanities, Basic Sciences, and Engineering. Then, 9 classes were randomly selected from each faculty. After obtaining an official consent for participation in the research, subjects were asked to complete the questionnaires. They were informed about the purpose of the research, confidentiality of their information, and possibility to leave the study at any stage. Inclusion criteria were being a university student, signing informed consent agreement, and having physical and psychological health. None of the participants had a history of severe medical or psychiatric disorders or visited the Student's Counselling Center and Health Center or any other healthcare center in the past 6 months. All participants were asked to complete Young Schema Questionnaire-Short Form (YSQ-SF), Defense Style Questionnaire (DSQ-40), and the Saving Inventory-Revised (SI-R). The students' demographic data included their educational status, field of study, marital status, and age.

Young Schema Questionnaire-Short Form (YSQ-SF) has 75 items and was developed by Young (1998) to evaluate 15 early maladaptive schemas in 5 domains. Each question is scored based on a 6-point scale ( 1 for "completely untrue of me", 6 for "describes me perfectly"), and each 5 question, evaluates 1 schema. If the mean score of each subscale is more than 25 , that schema is considered as inefficient. The scale validity by Cronbach's alpha for the test as a whole was 0.96, and high for all subscales (Waller, Meyer, \& Ohanian, 2001). This questionnaire has been validated in Iran by Ahi, Mohammadifar and Besharat (2007), in Tehran University, and its internal consistency using Cronbach's alpha was reported as 0.97 in female population and 0.98 in male population. Cronbach's alpha of YSQ-SF was obtained 0.95 in the current study. 
Defense Style Questionnaire (DSQ-40) was developed by Andrews, Singh and Bond (1993) as a research tool with 40 questions. It evaluates 20 defense mechanisms in terms of 3 defense styles of mature, neurotic, and immature in a 9-point Likert-type scale (from "strongly agree" to "strongly disagree"). Watson and Sinha (1998) found an average item-scale correlation of $\mathrm{r}=0.78$ for the 20 scales. Test-retest correlations in a 4-week period have been reported with an average of $r=0.66$ for the 20 scales (Andrews et al., 1993).

Cronbach's alpha coefficients for defense styles of mature, neurotic, and immature in a sample of university students were $0.75,0.74$, and 0.74 , respectively; 0.74 , $0.74,0.72$ for male students and $0.75,0.74$, and 0.74 for female students, which indicates acceptable internal congruency of Persian version of DSQ (Basharat, Sharifi, \& Iravani, 2001). In this study, Cronbach's alpha for the 3 defense styles of mature, neurotic, and immature were obtained as $0.80,0.79$ and 0.76 , respectively.

Saving Inventory-Revised (SI-R) questionnaire, developed by Frost and Gross (1993), is a 23-item self-report measure, comprising 3 subscales: difficulty discarding, clutter, and excessive acquisition. SI-R items are scored between 0 and 4 , with higher scores indicate greater hoarding severity. The validity and reliability of this questionnaire was examined by Mohammadzadeh (2009) in Iran. Sufficient concurrent validity was gained via simultaneous conduction of factor analysis and Padua Inventory. Reliability in terms of Cronbach's alpha coefficient was found as 0.91 , the internal consistency coefficient was 0.87, sand test-retest coefficient with a 4-week interval was 0.91 (Mohammadzadeh, 2009). In this study, Cronbach's alpha of the SI-R was obtained as 0.93 . The obtained data were analysed by performing descriptive Statistics as well as Pearson correlation and simultaneous multiple regression using SPSS.

\section{Results}

The educational level of samples were as follows: Associate degree (44\%), BA (38\%), and MA (18\%). They got their degrees in 9 majors of Geology $(13 \%)$, Law (12\%), English Teaching (11\%), Biology (10\%), Computer (21\%), Pure Chemistry (9\%), Accounting (11\%), Theology (9\%), and Business Management (31\%). The sample group included 149 (49.66\%) females, and $151(50.33 \%)$ males, aged from 19 to 31 years with the Mean \pm SD of $24.03 \pm 3.05$ years. Of all, $77 \%$ were single and $23 \%$ were married. Mean values and standard de-

Table 1. Mean \pm SD scores of research variables

\begin{tabular}{|c|c|c|c|}
\hline \multirow{2}{*}{ Variables } & Male Students ( $n=151)$ & Female Students ( $n=149)$ & Total $(\mathrm{N}=\mathbf{3 0 0})$ \\
\hline & Mean \pm SD & Mean \pm SD & Mean \pm SD \\
\hline Total (EMS) & $173.23 \pm 40.13$ & $172.75 \pm 40.12$ & $172.99 \pm 40.06$ \\
\hline Disconnection/rejection & $53.87 \pm 15.91$ & $53.44 \pm 15.74$ & $53.66 \pm 15.80$ \\
\hline Impaired autonomy/performance & $39.23 \pm 13.64$ & $39.28 \pm 12.14$ & $39.25 \pm 12.90$ \\
\hline Other-directedness & $25.17 \pm 6.37$ & $24.51 \pm 6.53$ & $24.84 \pm 6.45$ \\
\hline Over vigilance/inhibition & $29.07 \pm 7.21$ & $28.28 \pm 7.68$ & $28.68 \pm 7.45$ \\
\hline Impaired limits & $25.88 \pm 6.51$ & $27.22 \pm 7.37$ & $26.55 \pm 6.98$ \\
\hline Mature defense style & $46.62 \pm 9.06$ & $45.77 \pm 11.44$ & $46.20 \pm 10.30$ \\
\hline Neurotic defense style & $46.52 \pm 9.06$ & $46.47 \pm 12.60$ & $46.50 \pm 11.55$ \\
\hline Immature defense style & $123.41 \pm 27.55$ & $127.24 \pm 28.80$ & $125.31 \pm 28.19$ \\
\hline Total (hoarding behavior) & $39.55 \pm 14.03$ & $39.58 \pm 13.75$ & $39.57 \pm 13.87$ \\
\hline Clutter & $16.52 \pm 6.68$ & $16.95 \pm 6.57$ & $16.74 \pm 6.62$ \\
\hline Difficulty discarding & $10.60 \pm 5.14$ & $10.16 \pm 5.31$ & $10.38 \pm 5.22$ \\
\hline Acquisition & $12.42 \pm 4.52$ & $12.46 \pm 4.40$ & $12.44 \pm 4.45$ \\
\hline
\end{tabular}


Table 2. Correlation coefficients of defence styles and domains of EMS with hoarding behaviour in students

\begin{tabular}{|c|c|c|c|c|c|}
\hline & Variables & Clutter & $\begin{array}{l}\text { Difficulty } \\
\text { Discarding }\end{array}$ & Acquisition & $\begin{array}{c}\text { Total (Hoarding } \\
\text { Behaviour) }\end{array}$ \\
\hline \multirow{3}{*}{$\begin{array}{l}\text { Defense } \\
\text { styles }\end{array}$} & Mature defense style & -0.04 & 0.09 & 0.05 & 0.03 \\
\hline & Neurotic defense style & $0.14^{*}$ & $0.19 * *$ & $0.21 * *$ & $0.21 * *$ \\
\hline & Immature defense style & $0.23 * *$ & $0.25 * *$ & $0.32 * *$ & $0.31 * *$ \\
\hline \multirow{6}{*}{ EMS } & Disconnection/rejection & $0.30 * *$ & $0.27 * *$ & $0.27 * *$ & $0.33 * *$ \\
\hline & Impaired autonomy/performance & $0.32 * *$ & $0.27 * *$ & $0.29 * *$ & $0.35 * *$ \\
\hline & Other-directedness & $0.23 * *$ & $0.19 * *$ & $0.25 * *$ & $0.26 * *$ \\
\hline & Over vigilance/inhibition & $0.29 * *$ & 0.07 & $0.28 * *$ & $0.25 * *$ \\
\hline & Impaired limits & $0.36^{* *}$ & $0.14^{*}$ & $0.41 * *$ & $0.36^{* *}$ \\
\hline & Total (EMS) & $0.37 * *$ & $0.26 * *$ & $0.36 * *$ & $0.39 * *$ \\
\hline
\end{tabular}

viations corresponding to the variables under study are presented in Table 1.

Table 2 presents the correlation matrices of EMS and defence styles with hoarding behaviour. Neurotic and immature defence styles have positive and significant correlations with hoarding behaviour, and its subscales $(\mathrm{r}=0.05, \mathrm{P}<0.01)$. Also, the domains of EMS have positive and significant correlations with hoarding behaviour, and its subscales $(\mathrm{r}=0.05, \mathrm{P}<0.01)$.

Standard multiple linear regression (the enter method) was used to determine the contribution of each component of defense styles (mature, neurotic, and immature) in prediction of the level of hoarding behaviour. The results of regression analysis showed that analysis of variance was statistically significant $(\mathrm{F}=13.60, \mathrm{P}<0.001)$, and $12.1 \%$ of the hoarding behaviour variance was predicted based on the defense styles $\left(\mathrm{R}^{2}=12.1 \%\right)$. Regres- sion coefficients revealed that all 3 defence styles (mature defence style negatively, and immature and neurotic defence styles, positively) predict the variance of hoarding behaviour (Table 3).

Standard multiple linear regression (the enter method) was used to determine the contribution of each domain of EMS (disconnection/rejection, impaired autonomy and performance, Impaired limits, other-directedness and over vigilance/inhibition), in predicting level of hoarding severity. The results indicated that the analysis of variance was statistically significant $(\mathrm{F}=12.53, \mathrm{P}<0.001)$, and $17.6 \%$ of the hoarding behaviour variance was predicted, based on the EMS $\left(\mathrm{R}^{2}=17.6 \%\right)$. Regression coefficients revealed that domains of impaired autonomy/ performance and impaired limits of EMS, significantly predicted variance in hoarding behaviour (Table 4).

Table 3. The regression coefficients analysis of hoarding behaviour based on defense styles in students

\begin{tabular}{|c|c|c|c|c|c|}
\hline \multirow{3}{*}{ Model } & \multicolumn{3}{|c|}{ Coefficients } & \multirow{3}{*}{$\mathbf{t}$} & \multirow{3}{*}{ Sig. } \\
\hline & \multicolumn{2}{|c|}{ Standardized } & \multirow{2}{*}{$\begin{array}{c}\text { Unstandardized } \\
\text { B }\end{array}$} & & \\
\hline & Beta & SE & & & \\
\hline Constant & 22.808 & 4.168 & - & 5.472 & 0.001 \\
\hline Mature defense style & -0.223 & 0.088 & -0.166 & -2.538 & 0.012 \\
\hline Neurotic defense style & 0.176 & 0.083 & 0.146 & 2.121 & 0.035 \\
\hline Immature defense style & 0.151 & 0.031 & 0.306 & 4.797 & 0.001 \\
\hline
\end{tabular}


Table 4. The regression coefficients analysis of hoarding behaviour based on EMS in students

\begin{tabular}{|c|c|c|c|c|c|}
\hline \multirow{3}{*}{ Model } & \multicolumn{3}{|c|}{ Coefficients } & \multirow{3}{*}{$\mathbf{t}$} & \multirow{3}{*}{ Sig. } \\
\hline & \multicolumn{2}{|c|}{ Standardized } & \multirow{2}{*}{$\begin{array}{c}\text { Unstandardized } \\
\text { B }\end{array}$} & & \\
\hline & Beta & SE & & & \\
\hline Constant & 15.529 & 3.510 & - & 4.424 & 0.001 \\
\hline Disconnection/rejection & 0.080 & 0.071 & 0.091 & 1.130 & 0.259 \\
\hline Impaired autonomy/performance & 0.184 & 0.084 & 0.171 & 2.183 & 0.030 \\
\hline Other-directedness & 0.024 & 0.151 & 0.011 & 0.161 & 0.872 \\
\hline Over vigilance/inhibition & 0.005 & 0.134 & 0.003 & 0.038 & 0.969 \\
\hline Impaired limits & 0.455 & 0.145 & 0.229 & 3.129 & 0.002 \\
\hline
\end{tabular}

\section{Discussion}

The present study aimed to investigate the predictive role of EMS and defense mechanisms in hoarding disorder. The results indicate that hoarding behaviour and its components have a positive and significant relationship with neurotic and immature defense styles, but no significant relationship was found between hoarding behaviour and mature defence style, and all 3 defense styles were able to predict this disorder.

Although researchers disregarded the relationship between defense styles and mechanisms with hoarding behaviour, there are a number of studies which revealed the relationship between defense mechanisms and obsessive disorders that are in line with this research. For instance, Afzali, Fathi Ashtiani and Azad Fallah (2008), in a study compared the defense styles and mechanisms of individuals suffering from OCD and normal people. They reported that a significant difference exists between the two groups of individuals in relation to their defense styles, and that patients with OCD tend to more frequently use neurotic and immature styles. These results are consistent with the study results of Albucher et al. (1998), Johansen et al. (2011), and Shabanpour et al. (2012).

Defense mechanisms distort reality, and the severity of reality distortion in neurotic and immature defense are much higher than that in mature defense mechanisms. Therefore, defense mechanisms alternate one's recognition of self, reduce the awareness of oppositions, and as a result, change the feelings opposed to one's beliefs (Afzali, Fathi Ashtiani, \& Azad Fallah, 2008). This function of defense mechanisms in hoarding behaviour can be explained via Maier's (2004) review, which is a classifica- tion of hoarding and its phenomenological investigation Maier has taken advantage of egodystonic and egosyntonic terms to differentiate hoarding behaviour and OCD from a phenomenological perspective.

In egodystonic mode, individuals suffering from OCD have disturbing thoughts (obsession) which are in contrast with their needs and purposes (Ego). They show compulsive actions and dismiss their obsessive thoughts or conflict. On the other hand, in egosyntonic mode, individuals suffering from hoarding behaviour do not have disturbing thoughts or fantasies about objects or the rich to lead to ritualistic behaviour (Maier, 2004). Thus, neurotic and immature defense mechanisms in patients with hoarding behaviour might result in cognitive distortion, and reduced cognitive incongruity of ego, in relation to the stored objects and the rich.

This research reveals that hoarding behaviour and its components have a positively significant relationship with EMS domains, and are able to predict hoarding behaviour among the domains of EMS impaired autonomy/ performance and impaired limits. These results are in line with Frost's and Hartel's (1996) cognitive behavioural model, suggesting that interaction of some aspects of deficiency in data processing, defective beliefs about the essence of belongings, and the patterns of emotional avoidance cause hoarding behaviour in suffered individuals.

A review of cognitive behavioural models of hoarding behaviour reveals that hoarding is identified by troubles in forming interpersonal relationships, emotional attachment, and distorted beliefs, regarding objects (Frost \& Gross, 1993; Ayers, Wetherell, Golshan, \& Saxena, 2011). Also, previous research studies have demonstrat- 
ed that EMS has an evident role in obsessive disorders. For example, Atalay et al. (2008) reported that patients suffering from OCD had higher scores in EMS (social isolation, vulnerability to harm or illness, and cynicism) compared to the control group. EMS effects the individuals in their course of encoding, processing, and responding to environmental stimulators (Young, 1994).

Such structures protect the individuals against paralysing and intense emotions via their continuation processes, which commonly emerge following the activation and excitation of a schema. In this way, individuals unfortunately secure themselves against changes, preserve their negative content, and develop a wide range of personal, interpersonal, and social inefficiencies and problems (Young, 1994). Thus, it can be inferred that certain schemas, as it was presented in Frost's and Hartel's (1996) model, actually aid the continuation of this disorder in individuals suffering from hoarding behaviour by causing emotional attachment and distortion of information, regarding objects and the rich.

One limitation of this research was the study population, in which samples were only selected from students of Payame Noor University of Khoy and with regard to the cultural differences and diversity of Iranian society, the generalization of the results to all students should be taken with caution. We suggest more investigations in clinical groups and individuals with hoarding disorder, in order to obtain more accurate and useful information.

The present research results were consistent with previous theoretical and empirical literature, and provided sufficient evidence for the interaction of defense styles and EMS in hoarding behaviour. Considering the study results, this disorder can be treated by dynamic psychotherapy, psychoanalysis, and cognitive behavioural therapy. Finally, as this research is conducted in public community, it is suggested that research variables be explored in clinical groups to more accurately reveal their effects on hoarding behaviour.

\section{Ethical Considerations}

\section{Compliance with ethical guidelines}

All ethical principles were considered in this article. The participants were informed about the purpose of the research and its implementation stages; They were also assured about the confidentiality of their information; Moreover, They were allowed to leave the study whenever they wish, and if desired, the results of the research would be available to them.

\section{Funding}

This research did not receive any specific grant from funding agencies in the public, commercial, or not-forprofit sectors.

\section{Conflict of interest}

All authors certify that this manuscript has neither been published in whole nor in part, or being considered for publication elsewhere. The authors have no conflicts of interest to declare.

\section{Acknowledgments}

We would like to thank the individuals and organizations who generously shared their time and experience for the purposes of this study.

\section{References}

Afzali, M. H., Fathi Ashtiani, A., \& Azad Fallah. P. (2008). [The Study of defense styles \& mechanisms in patients with $\mathrm{Ob}$ sessive -compulsive disorder, generalized anxiety disorder \& social phobia disorder (Persian)]. Journal of Clinical Psychology, 1(1), 79-93. [DOI:10.22075/JCP.2017.1999]

Ahi, Gh., Mohammadifar, M. A., \& Besharat, M. A. (2007). [The psychometric properties of Young Schema QuestionnaireShort Form (YSQ-SF) (Persian)]. Psychology \& Educational Science, 37(3), 5-20.

Albucher, R. C., Abelson, J. L., \& Nesse, R. M. (1998). Defense mechanism changes in successfully treated patients with obsessive-compulsive disorder. American Journal of Psychiatry 155(4), 558-9. [DOI:10.1176/ajp.155.4.558]

American Psychiatric Association. (2013). Diagnostic and statistical manual of mental disorders (DSM-5®). Washington, D. C.: American Psychiatric Pub

Andrews, G., Singh, M., \& Bond, M. (1993). The Defense Style Questionnaire. Journal of Neroous and Mental Disease, 181(4) 246-56. [DOI:10.1097/00005053-199304000-00006] [PMID]

Atalay, H., Atalay, F., Karahan, D., \& Caliskan, M. (2008). Early maladaptive schemas activated in patients with obsessive compulsive disorder: A cross-sectional study. International Journal of Psychiatry in Clinical Practice, 12(4), 268-79. [DOI:10.1080/13651500802095004]

Ayers, C. R., Wetherell, J. L., Golshan, S., \& Saxena. S. (2011). Cognitive-behavioral therapy for geriatric compulsive hoarding. Behaviour Research and Therapy, 49(10), 689-94. [DOI:10.1016/j.brat.2011.07.002]

Beck, A. T. (1967). Depression: Clinical, experimental, and theoretical aspects. Philadelphia, Pennsylvania: University of Pennsylvania Press. 
Besharat, M. A., Sharifi, M., \& Irwani, M. (2001). [An investigation of the relationship between attachment styles and defense mechanisms (Persian)]. Journal of Psychology, 5(3), 277-89.

Bond, M., Gardner, S. T., Christian, J., \&Sigal,J. J. (1983). Empirical study of self-rated defense styles. Archives of General Psychiatry, 40(3), 333-8. [DOI:10.1001/archpsyc.1983.01790030103013]

Canale, A., \& Klontz, B. (2013). Hoarding disorder: It's more than just an obsession-implications for financial therapists and planners. Journal of Financial Therapy, 4(2), 4. [DOI:10.4148/1944-9771.1053]

Cramer, P. (2000). Defense mechanisms in psychology today: Further processes for adaptation. American Psychologist, 55(6), 637-46. [DOI:10.1037/0003-066X.55.6.637]

Frost, R. O., \& Gross, R. C. (1993). The hoarding of possessions. Behaviour Research and Therapy, 31(4), 367-81. [DOI:10.1016/0005-7967(93)90094-B]

Frost, R. O., \& Hartl, T. L. (1996). A cognitive-behavioral model of compulsive hoarding. Behaviour Research and Therapy, 34(4), 341-50. [DOI:10.1016/0005-7967(95)00071-2]

Frost, R. O., Steketee, G., \& Tolin, D. F. (2011). Comorbidity in hoarding disorder. Depression and Anxiety, 28(10), 876-84. [DOI:10.1002/da.20861]

Frost, R. O., Steketee, G., \& Williams, L. (2000). Hoarding: A community health problem. Health $\mathcal{E}$ Social Care in the Community, 8(4), 229-34. [DOI:10.1046/j.1365-2524.2000.00245.x]

Johansen, P. Ø., Krebs, T. S., Svartberg, M., Stiles, T. C., \& Holen, A. (2011). Change in defense mechanisms during short-term dynamic and cognitive therapy in patients with cluster $C$ personality disorders. The Journal of Nervous and Mental Disease, 199(9), 712-5. [DOI:10.1097/NMD.0b013e318229d6a7]

Kennedy, T., \& O'Neill, 1. (2012). Elder care: A resource for interprofessional providers: Hoarding Disorder. ELDER CARE. Retrieved from: https://aging.arizona.edu/sites/default/files/factsheet-pdfs/hoarding_disorder_1.pdf

Kim, J. E., Lee, S. W., \& Lee, S. J. (2014). Relationship between early maladaptive schemas and symptom dimensions in patients with obsessive-compulsive disorder. Psychiatry Research, 215(1), 134-40. [DOI:10.1016/j.psychres.2013.07.036]

Krejcie, R. V., \& Morgan, D. W. (1970). Determining sample size for research activities. Educational and Psychological Measurement, 30(3) 607-10. [DOI:10.1177/001316447003000308]

Maier, T. (2004). On phenomenology and classification of hoarding: A review. Acta Psychiatrica Scandinavica, 110(5), 323-37. [DOI:10.1111/j.1600-0447.2004.00402.x]

Mataix Cols, D., Frost, R. O., Pertusa, A., Clark, L. A., Saxena, S., Leckman, J. F., et al. (2010). Hoarding disorder: A new diagnosis for DSM-V. Depression and Anxiety, 27(6), 556-72. [DOI:10.1002/da.20693]

Mohammadzadeh, A. (2009). [Validation of Saving InventoryRevised (SI-R): Compulsive hoarding measure (Persian)]. Iranian Journal of Psychiatry and Clinical Psychology, 15(1), 33-41.

Pertusa, A., Fonseca, A. (2014). Hoarding behavior in other disorders. In: R. O. Frost, G. Steketee (Eds), The Oxford Handbook of Hoarding and Acquiring. New York: Oxford University Press. [DOI:10.1093/oxfordhb/9780199937783.013.010]
Shabanpour, R., Zahiroddin, A. R., Janbozorgi, M., \& Ghaeli, P. (2012). Assessment of defense styles and mechanisms in Iranian patients suffering from obsessive compulsive or panic disorders versus normal controls using Persian version of Defense Style Questionnaire-40. Iranian Journal of Psychiatry, 7(1), 31-5. [PMID] [PMCID]

Taylor, C. D., Bee, P., \& Haddock, G. (2017). Does schema therapy change schemas and symptoms? A systematic review across mental health disorders. Psychology and Psychotherapy: Theory, Research and Practice, 90(3), 456-79. [DOI:10.1111/papt.12112]

Tolin, D. F. (2011). Understanding and treating hoarding: A biopsychosocial perspective. Journal of Clinical Psychology, 67(5), 517-26. [DOI:10.1002/jclp.20795]

Vaillant, G. E. (1992). Ego mechanisms of defense: A guide for clinicians and researchers. Washington, D. C.: American Psychiatric Pub.

Walburg, V., \& Chiaramello, S. (2015). Link between early maladaptive schemas and defense mechanisms. European Review of Applied Psychology, 65(5), 221-6. [DOI:10.1016/j. erap.2015.07.003

Waller, G., Meyer, C., \& Ohanian, V. (2001). Psychometric properties of the long and short versions of the Young Schema Questionnaire: Core beliefs among bulimic and comparison women. Cognitive Therapy and Research, 25(2), 137-47. [DOI:10.1023/A:1026487018110]

Watson, D. C., \& Sinha, B. K. (1998). Gender, age, and cultural differences in the Defense Style Questionnaire-40. Journal of Clinical Psychology, 54(1), 67-75. [DOI:10.1002/(SICI)10974679(199801)54:13.0.CO;2-R

Wheaton, M. G., \& Van Meter, A. (2014). Comorbidity in hoarding disorder. In R. O. Frost, \& G. Steketee (Eds.), The Oxford Handbook of Hoarding and Acquiring (pp. 75-83) New York: Oxford University Press. [DOI:10.1093/oxford$\mathrm{hb} / 9780199937783.013 .003]$

Young, J. E. (1994). Cognitive therapy for personality disorders: A schema-focused approach, Rev. Sarasota, Florida: Professional Resource Press/Professional Resource Exchange.

Young, J. E. (1998). Young Schema-Questionnaire Short Form. New York: Cognitive Therapy Centre.

Young, J. E., Klosko, J. S., \& Weishaar, M. E. (2003). Schema therapy: A practitioner's guide. New York: Guilford Press. 